\title{
Typical Carcinoid: Cytological Diagnosis of a Case and Mimickers in Cytological Sampling Techniques with Brief Review of Literature.
}

\author{
Shashikant Singh ${ }^{1}$, Prajwala Gupta $^{1 *}$, Purnima Malhotra $^{1}$, Minakshi Bhardwaj ${ }^{1}$ and Desh Deepak ${ }^{2}$ \\ 'Dept. of Pathology, PGIMER Dr. RML Hospital, New Delhi \\ ${ }^{2}$ Dept. of Respiratory Medicine,PGIMER Dr.RML Hospital,New Delhi
}

\begin{abstract}
Typical carcinoids are the most well differentiated and least aggressive of pulmonary neuroendocrine tumors. Cytologic diagnosis on trans bronchial needle aspirate (TBNA) smears is quite diagnostic; however, may be challenging on other cytologic specimens like bronchial brushings and bronchial washings. We discuss such a case of typical carcinoid in a 30 years old female.
\end{abstract}

Keywords: Carcinoids, TBNA, Bronchial Washings, Bronchial Brushings

\section{Introduction}

Typical carcinoid tumor represents the benign spectrum of neuroendocrine tumors of lung. Diagnosis on histopathology is classical; however cytological diagnosis may be difficult with variation in the cytological sampling techniques. ${ }^{(1)}$ We describe a case of typical carcinoid diagnosed on trans bronchial needle aspirate (TBNA) smears and on bronchial brushing smears with elaboration of cytological mimickers.

\section{Case Report}

A 30 year old female presented to the pulmonary medicine outpatient department with complaints of cough and chest pain since 1 year, progressive breathlessness since 2 months and intermittent 3 episodes of hemoptysis. The patient was on anti-tubercular drug treatment for past three months being initiated at previous hospital; however, referred to our centre due to progressive worsening of the symptoms. There was no significant past history of any systemic illness, fever or any occupational exposure history.

On general examination, pallor was present. There was no palpable peripheral lymphadenopathy. Respiratory system examination revealed increased vocal fremitus and vocal resonance on left side of the chest. On auscultation, there was diminished air entry on the left side. Other systems had no abnormality detected. Complete blood count revealed low hemoglobin. Other hematological and routine biochemical parameters were within normal range. Sputum for acid fast bacilli (AFB) was negative.

Chest X-Ray showed findings of left upper lobe collapse. Contrast enhanced computerized tomography (CECT) scan showed evidence of intensely enhancing intraluminal soft tissue lesion measuring 16.9 x 14.6 × $8.4 \mathrm{~mm}$ involving proximal left upper lobe bronchus approximately $3.2 \mathrm{~cm}$ away from carina with collapse of left upper bronchus[Fig 1a]. Bronchoscopy was done and revealed $15 \times 14 \mathrm{~mm}$ smooth, glistening mass which was nearly occluding the left main bronchus at the level of left upper lobe[Fig 1b].

Trans bronchial needle aspiration(TBNA), bronchial brushings were done from the mass and multiple smears were made. Bronchial washings were performed on the left side. All these samples were sent to cytology laboratory for further processing and examination. The TBNA and brushing smears were air dried and fixed in $95 \%$ alcohol for subsequent staining with Giemsa and Papanicolaou stain subsequently. Cytospin smear preparation was made from the bronchial washing with aforesaid staining.

The TBNA smears showed high cellularity, revealing tumor cells in fragments with many traversing capillaries and cells adhering around them in groups, many singly scattered and focal tubule like arrangement[Fig2a]. These cells were relatively monotonous with plasmacytoid appearance; having eccentric nucleus, scant to moderate amount of pale cytoplasm with few cells showing indistinct cell border. nucleus was uniform, round to oval with stippled chromatin and inconspicuous nucleoli[Fig2b].

Focal nuclear overlapping and overcrowding were also seen. Occasional bi-nucleate cells were seen. No mitosis and necrosis was noted. Many benign bronchial epithelial cells were seen in clusters, groups and singly along with focal acute inflammatory cells. Background was haemorrhagic. Considering all the cytomorphological features, a diagnosis of typical carcinoid was given. Bronchial brush smears revealed numerous benign bronchial epithelial cells. 
Focally, revealed fragment with tumor cells seen adhering around blood vessel[Fig 2c]. However, the cells seen were mostly with poorly preserved cytoplasm and mimicking lymphocytes with occasional intact cells.

Smears from the bronchial washings revealed scant cellularity. However, very occasional small cell group with scant cytoplasm was seen along with benign bronchial epithelial cells for which a possibility of hyperplastic bronchial basal cells was considered. Concurrent biopsy was tried during bronchoscopy which on histopathological examination revealed a diagnosis of typical carcinoid[Fig 2d].

Table 1-Cytological mimickers of bronchial carcinoid tumor.

\begin{tabular}{|c|c|}
\hline CYTOLOGICAL MIMICKERS & CYTOMORPHOLOGY \\
\hline \multicolumn{2}{|r|}{ Non-Neoplastic } \\
\hline 1)Reactive Bronchial Epithelial Cell & $\begin{array}{l}\text { - Cells predominantly in tissue fragments. } \\
\text { Cells are round to cuboidal with high nuclear/cytoplasmic ratio and scant } \\
\text { cytoplasm with evenly distributed fine chromatin. } \\
\text { - Nuclear moulding, karyorrhexis and necrosis are not seen. }\end{array}$ \\
\hline $\begin{array}{l}\text { 2)Lymphocytes(In Follicular Bronchitis } \\
\text { And Lymphoid Hyperplasia) }\end{array}$ & $\begin{array}{l}\text { - Scattered mononuclear cells. } \\
\text { Mature lymphocytes or polymorphic lymphoid cell population with tingible } \\
\text { body macrophages. } \\
\text { - Nuclear moulding, karyorrhexis and necrosis are not seen. }\end{array}$ \\
\hline \multicolumn{2}{|r|}{ Neoplastic } \\
\hline 1)Atypical Carcinoid & $\begin{array}{l}\text { - Cells in small clusters or acinar groups } \\
\text { - Greater pleomorphism, coarser chromatin,prominent nucleoli compared to } \\
\text { typical carcinoid } \\
\text { - Mitosis and focal necrosis may be present. }\end{array}$ \\
\hline 2)Small Cell Carcinoma & $\begin{array}{l}\text { - Cells in loose cohesive clusters, syncytial tissue fragments and singly } \\
\text { scattered. } \\
\text { - Cells with high N/C ratio,scant cytoplasm and coarse granular stippled } \\
\text { chromatin } \\
\text { - Nuclear moulding, brisk mitosis and necrotic background are frequent. }\end{array}$ \\
\hline 3)Adenocarcinoma & $\begin{array}{l}\text { - Cellular 3-Dimensional clusters, papillary fronds, individual cells or acinar } \\
\text { (glandular) arrangements. } \\
\text { Columnar, cuboidal or polygonal cells with variable cell size, fine vacuolated } \\
\text { cytoplasm, round to oval nucleus; often eccentric, finely granular chromatin } \\
\text { and prominent nucleoli } \\
\text { - Nuclear moulding not seen. }\end{array}$ \\
\hline 4)Non Hodgkin Lymphoma & $\begin{array}{l}\text { - Discohesive, singly scatterd monomorphic cell population. } \\
\text { - Atypical lymphoid cells with scant cytoplasm, high N/C ratio and fine to coarse } \\
\text { nuclear chromatin with variable nucleoli. } \\
\text { - Nuclear moulding not seen. }\end{array}$ \\
\hline 5)Adenoid Cystic Carcinoma & $\begin{array}{l}\text { - Cells in loose cohesive clusters, syncytial and cup shaped tissue fragements } \\
\text { with spaces containing acellular pink hyaline globules. } \\
\text { Small cells with high N/C ratio,smooth nuclear membrane, hyperchromasia } \\
\text { and scant cytoplasm. } \\
\text { Background is hemorrhagic. }\end{array}$ \\
\hline
\end{tabular}




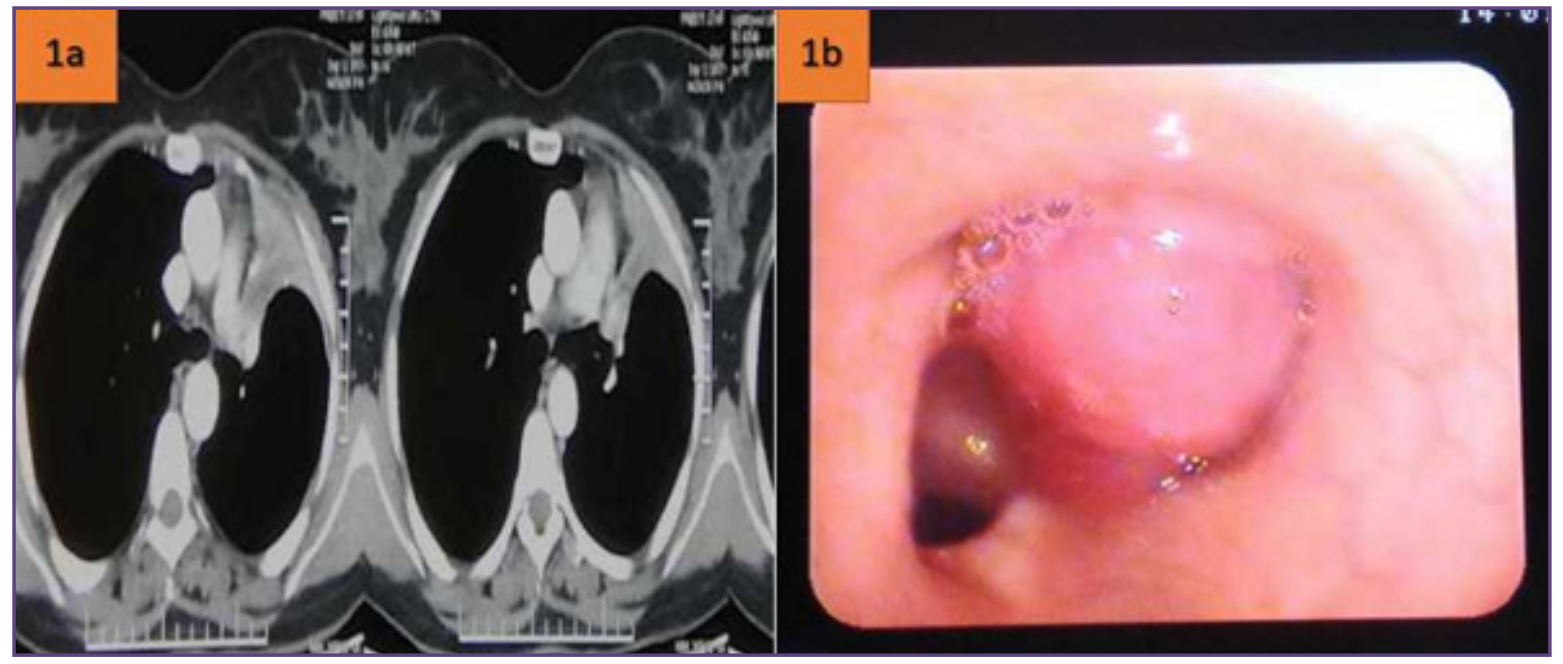

Fig. 1: a)-Contrast enhanced computed tomography (CECT) chest- Intensely enhancing endobronchial lesion in the origin of left upper lobe bronchus.Distal collapse of upper lobe.; b)-Bronchoscopy- A smooth glistening encapsulate mass nearly occluding left main bronchus.

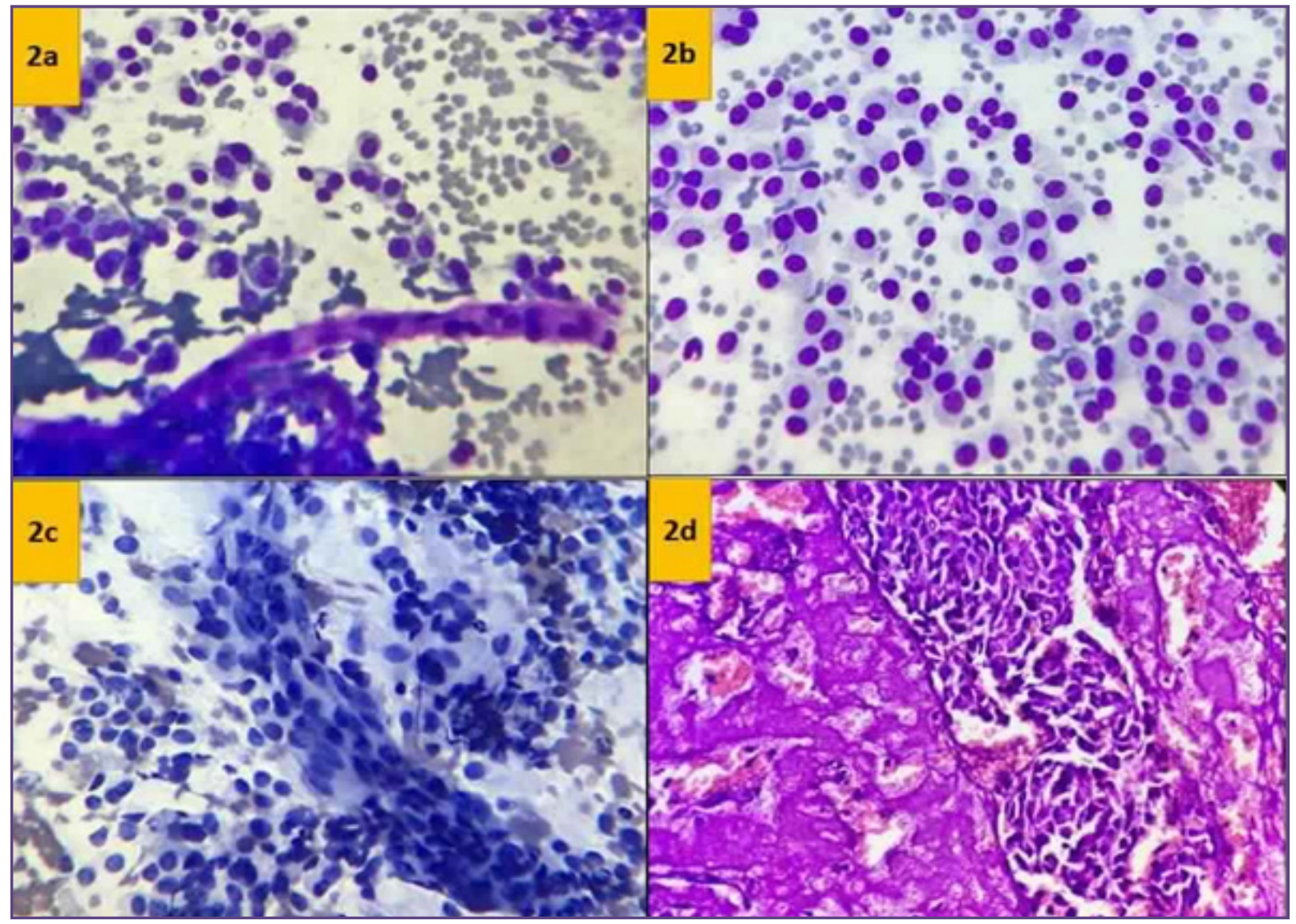

Fig. 2 a) FNAC smear - Cellular smear with tumor cells seen singly scattered and in loose groups around the vessels.[Giemsa, x100]; b)-Monomorphic plasmacytoid cells with eccentrically placed nucleus, salt and pepper chromatin, Inconspicous nucleoli \&pale cytoplasm.[Giemsa, x400]; c) Bronchial brushing smear- Occasional foci of tumor cells seen adhered around the blood vessels.[Giemsa, x400]; d) Monomorphic tumor cells of carcinoid with inconspicous nucleoli.[Hematoxylin\& Eosin,100x]. 


\section{Discussion}

Typical carcinoid tumors of the lung represent the most well differentiated and least biologically aggressive type of pulmonary neuroendocrine tumor. ${ }^{1}$ These tumors characteristically grow slowly and tend to metastasize infrequently. Approximately $75 \%$ of patients present with central tumors, and among these $52 \%$ are symptomatic. ${ }^{2}$ The common symptoms are cough, haemoptysis, wheeze, recurrent pneumonia or chest pain. These symptoms are attributed to the degree of endobronchial occlusion and the vascularity of the tumor. ${ }^{3,4}$ Atypical carcinoid tumors are located peripherally and metastasize at a considerably higher rate than typical carcinoid tumors and, therefore, carry a worse prognosis. Tumors that are centrally located are easily evaluated through fibre optic bronchoscopy (FOB) and bronchial brushings can easily be performed. ${ }^{5}$ Carcinoids being vascular in nature, risk of haemorrhage obiviates biopsy. Hence, cytological specimens give an advantage over the biopsy in diagnosis. ${ }^{6,7}$ Bronchoscopic evaluation of the lesion is important to assess the gross nature of tumor giving us a clue regarding the subsequent cytological yield. ${ }^{6}$ Well defined nodular lesion with intact epithelium will give poor tumor fragment on bronchial brush as compared to ulcerative or necrotic lesion. Bronchial brushing technique has the advantage over bronchial washings that the intact surface epithelium of the lesion is scraped with a brush, thus dislodging the cells from the surface of the lesions. ${ }^{4}$ Bronchial brush also carries low risk of haemorrhage over TBNA and biopsy. Cytologically, typical carcinoid tumor on TBNA smears consists of single cells or loose clusters of cells; occasionally with trabeculae or three-dimensional patterns. There may be plexiform arrangement of small blood vessels with adherent tumor cell. ${ }^{8}$ The cytoplasm may be stripped from the nucleus, but when present is scant to moderate and homogenous to finely granular. The nuclei are small, round to oval and placed central or slightly eccentric with smooth nuclear membranes coarse granular chromatin ["salt and pepper"] with small distinct nucleolus. ${ }^{9}$ They are differentiated from other neuroendocrine tumors on the basis of mitosis and necrosis.

The bland, benign appearance of the tumor cells is another major contributing factor in the low identification rate of this tumor. The cytomorphological features of the common cytological mimickers comprising both non neoplastic and neoplastic lesions may be helpful in avoiding misdiagnosis[Table 1]. Morphologically, bronchial epithelial cells may mimic neuroendocrine cells, both in architecture and cytology. The bronchial cells with scant cytoplasm and acinar arrangement closely resemble neuroendocrine tumors. The possible reasons for a false-negative report on initial cytology include the paucity of tumor cell fragments in the bronchial washings and their bland appearance; often being mistaken for benign bronchial cells. ${ }^{10}$ This was probably the reason for dilemma in the smears from bronchial wash in our case. Typical carcinoid may also mimic welldifferentiated adenocarcinoma due to its polygonal cells often forming acini. The overall cytological details and nuclear chromatin may help in diagnosis as was seen in our TBNA smears. Scattered naked nuclei of carcinoid can resemble hyperplastic reserve cells, lymphocytes, smallcell carcinoma.$^{6,8}$ The cellular yield is often diagnostic on TBNA but carries risk of bleeding and compared to this bronchial brushing smears may not always be diagnostic but hemorrhage is less likely. However; a combined TBNA and bronchial brushing smears may be valuable cytological material.

\section{Conclusion}

To establish a diagnosis of carcinoid on bronchial brushing smears, a suspected bronchoscopic finding should prompt careful examination of bronchial brushing smears. For both TBNA and bronchial brushing smears, the cytological mimickers should be considered before concluding the diagnosis of carcinoid tumor.

\section{Reference}

1. Travis WD, Brambilla E, Muller-Hermelink HK, Harris CC. 1st ed. Lyon: IARC Press; 2004. Pathology and genetics of tumors of the lung, pleura, thymus and heart; pp. 31-62.

2. Johnston WW, Elson CE. Respiratory tract. In: Bibbo M, editor. Comprehensive cytopathology. 3rd ed. Philadelphia: W.B. Saunders Company; 2008. pp. 325-401.

3. Oberg K, Jelic S. ESMO Guidelines Working Group. Neuroendocrine bronchial and thymic tumors: ESMO clinical recommendation for diagnosis, treatment and follow-up. Ann Oncol. 2009;20:147-9.

4. Stoll LM, Johnson MW, Burroughs F, Li QK. Cytologic diagnosis and differential diagnosis of lung carcinoid tumors a retrospective study of 63 cases with histologic correlation. Cancer Cytopathol. 2010;118:457-67.

5. Anderson C, Ludwig ME, O’Donnell M, Garcia N. Fine needle aspiration cytology of pulmonary carcinoid tumors. Acta Cytol 1990;34: 505-10.

6. Aron M, Kapila K, Verma K. Carcinoid tumors of the lung: a diagnostic challenge in bronchial washings. Diagn Cytopathol. 2004;30:62-6

7. Córdoba A, de Llano P, Arrechea MA, Beloqui R, Gómez ML. Partial expectoration of a typical carcinoid: report of a case with diagnosis on sputum cytology. Acta Cytol. 2006;50:581-3. 
8. Idowu MO, Powers CN. Lung cancer cytology: potential pitfalls and mimics - a review. Int J Clin Exp Pathol. 2010;3:367-85

9. Mayumi K, Kuniko A, Yukiko A, Yoshiro E. Capillary network contributing to the cytological diagnosis of bronchial carcinoid. J Jpn Soc Clin Cytol. 2000;39:109-10.

10. Nguyen GK. Cytopathology of pulmonary carcinoid tumors in sputum and bronchial washings. Acta Cytol 1995;39:1152-60.

*Corresponding author:

Dr.PrajwalaGupta(M.D.), Associate Professor, Department of Pathology, Room No 302, 3rd floor, OPD Building, Dr RML Hospital,

Baba Kharak Singh Maarg, New Delhi-01 INDIA

Phone: +91 9910306227

Email: prajwala2000@yahoo.com

\section{Financial or other Competing Interests: None.}

